\title{
Aproximación teórica a la región histórica y al catolicismo popular de la Meseta de los Pueblos
}

Recepción: 22-01-2016 / Aceptación: 07-03-2016

Mario Miguel Cienfuegos Narváez

\begin{abstract}
Resumen
En este ensayo se busca la compresión de la región histórica y sus implicaciones, las cuales pasan por esclarecimiento de categorías teóricas conexas, cuya acotación y acercamiento permiten aclarar las diferencias y similitudes conceptuales de interés para el análisis. De la misma manera, se estudia la región histórica la cual es posible entenderla y evidenciarla por medio de la evolución y desarrollo histórico y cultural de elementos discriminados. Un ejemplo, es el discurso que parte del seno de la religiosidad popular, en lo que se ha llamado circuito ritual religioso de ascendencia católico popular, sobre el cual se sustenta parte del estudio. Todo esto a partir de las reflexiones teórico-prácticas que dan lugar a nuevos conocimientos.
\end{abstract}

Palabras claves: Región histórica, religiosidad popular, circuito ritual religioso, cosmovisión

\begin{abstract}
Understanding the historical region implies necessarily pass to clarify related theoretical categories, this way the shoulder and approach help to clarify the differences and similarities and then take conceptual position of interest for analysis. In the same way the historical region is possible to understand and let see through analysis of evolution and historical and cultural development of certain elements that are discriminated agains, according to the interests of those who write, the example here content, generates a speech that part of within popular religiosity, in which here it has been called religious ritual circuit. All this from the theoretical and practical reflections that give rise to new knowledge.
\end{abstract}

Keywords : Historical Region, popular religiosity, religious ritual circuit, worldview

\section{Introducción}

En este artículo se pretende en primer lugar acercarse a las definiciones de territorio, espacio, región y región histórica para dar sentido al argumento aquí desarrollado. Las definiciones de las fronteras o alcances de estos conceptos (diferencias, similitudes) permite seguir un itinerario teórico de los mismos y la toma de posición de quien escribe, dando paso a los argumentos sobre la liquidez de las fronteras

Se hacen ciertas acotaciones sobre las peregrinaciones, romerías, procesiones y recorridos rituales. Sus elementos constitutivos que los acercan y alejan a las realidades que se estudian. Todas ellas como el vehículo para entender las dinámicas culturales que permiten redimensionar el territorio en términos de catolicismo popular que se vive en una parte de la meseta de los pueblos, de manera que se afiance un nuevo entendimiento tratado en el estudio como encuentros rituales.

Las reflexiones teóricas surgen de las experiencias culturales en el lugar conocido como la Meseta de los Pueblos. Un espacio geográfico elevado a aproximadamente 
$600 \mathrm{msnm}$, ubicada al oeste del territorio de Nicaragua (en la franja del Pacífico) compartida por los departamentos de Managua, Carazo, Masaya y Granada. Los pueblos asentados en este territorio, en su mayoría, tienen origen prehispánico, de donde se deriva sus tradiciones gastronómicas, económicas, folklóricas y sobre todo sus fiestas patronales.

En el extremo norte de la meseta se ubican los municipios de Diriamba, Dolores, San Marcos y Jinotepe, todos del departamento de Carazo. En el aspecto religioso, cada uno de ellos cuenta con su santo patrón titular, a quienes se les celebran sus fiestas en diferentes fechas del año. Una particularidad de estas festividades es la conformación de un circuito ritual de fiestas, de manera que se observa como una sola región.

La metodología que se siguió para la elaboración de este artículo científico, combina experiencias prácticas y conocimientos previos, sobre el tema de las peregrinaciones y la conformación de las regiones históricas. De tal manera que se parte de los trabajos escritos sobre el tema y se coteja con las prácticas culturales que en los últimos tiempos se viene dando en cada uno de esos espacios geográficos referido a estas celebraciones religiosas y su impronta popular.

El trabajo está divido en cuatro partes o momentos: El primero, problematiza acerca de lo que es espacio, territorio, región y región histórica. El segundo momentos versa sobre el tratamiento y discusiones teóricas surgidas del tema de las peregrinaciones, procesiones, romerías y recorridos rituales, dando cabidas a la nueva propuesta. El tercero, vincula el elemento histórico y las propuestas teóricas antes mencionadas. Finalmente, se presentan las conclusiones donde se señalan los aspectos fundamentales, de mayor importancia y que forman parte de la discusión en este artículo.

\section{Espacio, territorio, región y región histórica: reflexiones para su abordaje}

Definir el territorio es un salto a la memoria que indica tierra y recursos. Geógrafos, físicos, geólogos y otros científicos apoyan esta noción. El territorio también suele verse desde lo económico por el valor comercial de los recursos explotables que contiene, desde lo político - administrativo como elemento jurídico de división y administración de lo público. En este caso particular se trata de ver el territorio como una relación de seres humanos con la naturaleza, donde se crean y se recrean los espacios por medio de la itinerancia, dando vida en ocasiones desconocida, poco comprensible.

Un espacio territorial que cobra vida gracias a las dinámicas culturales desarrollada por los grupos humanos con ella y en ella. De tal manera, que se opera una mediación entre el espacio vivido y el espacio creado.

El espacio vivido es un tema tratado desde la geografía humana como el espacio físico. Es el lugar de uso y reproducción de las sociedades humanas, la sicología con el tema de las representaciones sociales del espacio, filósofos, urbanistas y otros cientistas, quienes desde sus perspectivas disciplinares han ahondado sobre el mismo. Si bien, este concepto nace desde la geografía, las dimensiones de las ciencias han creado sus propias reflexiones. De manera que Alicia Lindón y Daniel Hiernaux (2006) apuntan la conceptualización de espacio vivido propuesto por Armand Frémont en 1974 y luego desarrollado en 1976 por Jaques Chevalier en los siguientes términos:

la propuesta del espacio vivido no se limita a reconocer lugares frecuentados, definir itinerarios, situar al hombrehabitante en su cuadro familiar de existencia [...] sino focalizar la mirada en la relación con las representaciones [...] es decir superar el espacio extensión (o 
espacio-soporte), para abordar la noción de representación (imagen) del espacio, planteado una nueva pregunta: ¿Cómo ven los hombres el espacio? [...] El espacio vivido es reivindicado como un espacio cargado de valores (Chevalier, en Lindón y Hiernaux 2006: 382)

El espacio creado por su parte, tiene una connotación claramente utilitarista, considerado por Lefebvre (1974) como puntos de confluencia e influencia de flujos que ocupan ese espacio. Situaciones como la construcción, la urbanización, las inversiones, la venta y la compra del espacio como totalidad y la especulación.

Se platean dos realidades del espacio. Por un lado, el espacio creado nos remite a la situación político-administrativa, el trazo de calles, calzadas, donde el llamado ordenamiento territorial tiene supremacía, y las municipalidades como órgano rector de descentralización gubernamental, sean vistas como grandes empresas encargadas de obras de infraestructura. El otro, el espacio vivido está constituido por las formas de significación que le imprime la cultura.

El concepto de territorio, no dista mucho del concepto de espacio. Gustavo Montañez y Ovidio Delgado (1998) hacen una acotación sobre el primer concepto, ofreciendo ciertas características; entre las que destacan, verlo como el escenario de las relaciones sociales y no solamente el marco espacial que delimita el dominio soberano del Estado. Es el espacio de poder de gestión y dominio del estado, es una construcción social, que tiene como característica, ser móvil, mutable y desequilibrado por la realidad geo social cambiante y que requiere por lo tanto, nuevas formas de relaciones de organización; también es sentido de pertinencia e identidad, de conciencia regional, al igual que el ejercicio de ciudadanía.

El territorio necesariamente nos lleva al concepto de territorialidad. Para tales efectos Gustavo Montañez (1998) la define como: "el grado de control de una determinada porción de espacio geográfico por una persona, un grupo social, un grupo étnico, una compañia multinacional, un Estado o un bloque de estados" (Montañez: 198).

En la cita anterior, el autor, hace referencia a las prácticas tendientes a garantizar la apropiación, conocimiento, permanencia y discriminación del territorio como expresiones de organización institucionales, como el estado, las empresas o agentes sociales. Vemos que espacio vivido, creado, y territorio como encuentros y acercamientos teóricos, son expresiones materiales y simbólicas que están presentes en el uso de los mismos.

Falta observar las acotaciones alrededor del concepto de región. Cualquier interés por la búsqueda de un concepto de región, pasa por los estudios geográficos o de políticas públicas, por la importancia que tiene en términos administrativos, políticos, económicos enmarcados dentro de límites o fronteras.

La realidad teórica no dista de concebir la región desde lo físico. Sin embargo, autores como Pierre Bordieau le confieren sentido social dado que las regiones y fronteras no són únicamente físico-geográfico sino también sociales, culturales. Este autor, señala que:

La etimología de la palabra región (regio) tal como la describe Emile Benveniste conduce al principio de la división, acto mágico, es decir propiamente sociales, de diacrisis, que introduce por decreto una discontinuidad decisoria en la continuidad natural (entre las regiones del espacio pero también entre las edades, los sexos, etc.), redefine, el acto que consiste en "trazar en líneas rectas las fronteras", a separar "el interior y el exterior, el reino de lo sagrado y el reino de lo profano, el territorio nacional y el 
territorio extranjero", es un acto religioso realizado por el personaje investido de la más alta autoridad (Bordieau; 2006: pág. 170)

Lo que se persigue es darle carácter social a la discusión sobre el espacio, el territorio y la región, por lo que es importante destacar el carácter humano que la historia aporta a los estudios de la región. Briggitte Boehm (1997), acota sobre esta propuesta y afirma que la regionalidad se establece por una centralidad donde es necesario el reconocimiento de la historicidad cuya variabilidad responde a los momentos cronológicos.

Como se ve, la discusión está dirigida a considerar la región desde la conformación histórica. Ivette García presenta una reflexión alrededor de esta temática, y asegura que es:

...la existencia de un espacio geográfico social... en el que confluyen una serie de características económicas, sociales, políticas, culturales e ideológicas, que concurren de manera armónica y homogénea y cuyos vínculos en el tiempo largo, producen una identidad que perdura en su trayectoria. (García, 2004:267).

De manera que la región histórica está constituida por hechos y experiencias sociales concretas, mientras que espacio, territorio, región aluden a diferentes acepciones según el campo disciplinario desde el que se visite. El planteamiento continúa con el acercamiento al catolicismo popular, buscando demostrar que la región histórica tiene muchos componentes, desde los que se puede estudiar. Así se tiene el contexto económico, político, de las artes, de la gestión de riesgos y los desastres; vulnerabilidades ambientales, sociales, desde el campo de las relaciones de poder; pero también desde el análisis de la perspectiva religiosa.

\section{El catolicismo popular para la definición de la región histórica}

En este acápite se comienza por la definición de lo que se entiende por catolicismo popular. Para José Luis González (2000) es un conjunto de creencias, prácticas y rituales: normatividad ética, cosmovisión y construcciones culturales que logran la apropiación de lo cristiano. Esta concepción surge en el seno de los grupos considerados como marginales o subalternos, visto desde la cultura oficial y hegemónica. En una concepción que se contrapone, al menos conceptual, al catolicismo oficial.

Las peregrinaciones, procesiones, romerías y recorridos rituales se encuentran contenidas en el ámbito del catolicismo popular, aunque su contenido conceptual varía, siendo útil esta discusión para tomar posición que permitan nuevos enfoques explicativos o conceptuales propios. Para iniciar, es bueno retomar la idea de "peregrino" de Marcelino Agís Villaverde (2008) y el de "peregrinación".

"La palabra "peregrino" viene del latín "peregrinus", procedente a su vez de "peragrare", que significa ir por los campos ("agros"). Razón por la que fue ampliando su semántica y acabó designando a todo el que va o viene del extranjero" (Agís Villaverde; 2008: pág. 02)

Éste autor aclara que la peregrinación incluye un triple encuentro. Por un lado, el encuentro consigo mismo y las dificultades planteadas al viajar, así mismo el encuentro con los otros que se desplazan a la par y que comparten ideas, sentimientos, identidad, finalmente, el encuentro con Dios, razón última por la que merece la pena todos los sacrificios del camino.

$\mathrm{Al}$ darle sentido ritual a las peregrinaciones, Víctor y Edith Turner (1978) las ubican en los rituales de paso, y el peregrino en la fase liminal, siendo su condición transitoria, 
temporal. Hay que dejar planteado que peregrinar es una acción deliberada y discriminada por el peregrino, no existiendo obligación aparente para emprender el viaje. Lo contrario sucede en sociedades más tradicionales donde la participación en estos rituales tiene un rango de obligatoriedad, razón por la cual Turner hace referencia a esta condición con el término liminoide y no liminal.

Las peregrinaciones en palabras de Turner (1978) forman una comunidad temporal que denomina communitas. Tiene por característica estar conformada por circunstancias excepcionales y temporales, en este caso el religioso, en contraste con la estructura social, que es estable y perdurable en el tiempo, es el espacio de la vida cotidiana.

Las peregrinaciones tienen motivos precisos. Al respeto, Radoslav Hlúšek (2013) las clasifica en tres momentos o grupos. La clasificación que hace este autor, permite aclarar que el carácter, los objetivos, las intenciones de los que peregrinan no son las mismas, a pesar de que compartan el espacio ritual.

Como se señaló arriba, Hlúšek (2013) habla de las motivaciones para participar en las peregrinaciones, las cuales se pueden agrupar en tres grupos. Aclara de antemano que estas categorías no existen separadas sino complementadas de manera mutua. En el primer grupo designado como espirituales, sobresale la visita del lugar sagrado para honrar a su patrón. También se puede añadir la penitencia, cuando la peregrinación sirve como perdón de pecados. El segundo se denomina como intencionados ya que el objetivo del peregrino es pedir o agradecer por algo. Se incluyen las peticiones, ruegos, agradecimientos y las promesas en las que el patrón del lugar sirve como testigo. Y por fin, en el último grupo, llamado secular, pertenecen el turismo y curiosidad.
Tamara Mudarra Vidal (2015) da ciertas luces sobre estas concepciones. Esta autora explica que romería y romero hacen referencia a los que viajaban a Roma, considerado tiempos atrás un como lugar sagrado; el concepto de peregrino señala, hace referencia a extranjero o viajero. Ahora bien, explica que existe cercanía conceptual entre peregrinaciones y procesiones, porque al fin y al cabo son movilizaciones de conglomerado de personas a lugares sagrados cuyas dimensiones pueden ser de tipo lúdico, festivo o religioso. En relación a este tema, José Luis González señala puntos en común y de distinción dentro de estas expresiones:

Las peregrinaciones y las procesiones fueron rituales privilegiados. Ambos rituales tienen en común el contenido simbólico de la caminata como parte de un lenguaje total en el que el cuerpo, el esfuerzo y el sacrificio se incorporan. Sin embargo, mientras que en la procesión el poder sagrado sale al encuentro de lo profano y lo cotidiano, en la peregrinación se camina hacia los lugares sagrados para recibir el beneficio de lo sobrenatural. (González; 2000: pág113)

Es interesante la propuesta de González (2000) dado que se centra en el encuentro de lo sagrado a lo profano. En este recuento teórico y conceptual, la propuesta de Enrico Straffi (2005) es pertinente mencionarla, puesto que considera denominarla "recorrido ritual" y no peregrinaciones a la acción religiosa de caminara hacia los lugares sagrados dado que es: "La realización de un traslado, por parte de un grupo de encargados especializados pertenecientes a una colectividad, a uno o más lugares sagrados, venerados por la misma colectividad, que se encuentran afuera del paisaje comúnmente vivido por sus miembros" (pág: 30)

Hasta aquí se puede argumentar que las concepciones de peregrinación, romería, procesión y recorrido ritual, hacen referencia indistintamente a traslados $y$ 
movimientos de personas, al encuentro de lugares considerados sagrados, revestidos simbólicamente de espiritualidad. Ahora bien, estas prácticas rituales ubicadas desde el punto de vista teórico que guían el trabajo de investigación en curso, debe situarse en un espacio histórico-cultural, por lo tanto se debe de hablar de frontera, comenzando con dos particularidades a tener en cuenta.

La primera particularidad señala que la región histórica debe trazar ciertos límites que pueden ser: físicos, históricos y culturales. Dado que esta investigación está localizada en la "Meseta de los Pueblos", donde se convergen, desde el punto de vista de las celebraciones religiosas, tres santos: Santiago, San Marcos y San Sebastián, patronos de los municipios de Jinotepe, San Marcos y Diriamba respectivamente, se está ante un fenómeno cultural de características particulares en el país, haciendo que otros límites que sustenta la región sean complementarios desde el punto de vista de la definición.

La segunda, hace referencia a una particularidad de las festividades, que sin negar la tradición religiosa popular de fuerte raigambre local (municipal, comunitario o de barrio) de las procesiones que celebran los santos tutelares, donde tiene preeminencia los recorridos internos, destaca la ausencia de límites geográficos impuestos por las instituciones estatales. Las celebraciones religiosas de los santos arriba señalados, trascienden los límites rígidos de las fronteras político administrativas, prevaleciendo el sentido y la fuerza cultural de los encuentros y las sociabilidades que de ello emanan.

Es importante destacar desde el punto de vista del tratamiento teórico de la peregrinación, que la gente van a los lugares sagrados, pero en el caso particular de la Meseta de los Pueblos, los tres santos hermanos se visitan con sus creyentes en cada una de sus localidades, no mediando un lugar sagrado específico donde vayan los santos, sino que varios o distintos los lugares tomado como sagrados. En este caso, el concepto tradicional de peregrinación que considera que la gente va donde se encuentran las cosas y los objetos sagrados, no encaja, porque en el caso del estudio, son los santos los que visitan a otros santos acompañados de la gente, encontrándonos con un "circuito ritual religioso".

Ahora bien, por "circuito ritual religioso" debe entenderse como las prácticas seguidas por el calendario religioso festivo relativo a cada santo y donde convergen todos de manera sincronizada. Los santos San Sebastián, San Marcos y Santiago, tienen diferentes fechas en el calendario religioso católico anual. Sus celebraciones son de carácter rotativo según las fechas de celebración correspondiente a cada santo patrón. De manera que la movilización a la morada de estos, se produce de acuerdo con el santo en turno de celebración.

Lo sagrado en el circuito ritual religioso, al no contar con un espacio físico único sino diverso, movible, según corresponda la fecha de celebración conjunta, le da la impronta de lo novedoso. Esta práctica ritual refuerza las redes sociales, políticas, económicas, familiares, vecinales, y comunitarias, en tanto que producen un espacio para el encuentro, no solo de los santos sino de los miembros de los comités de fiestas, los creyentes, promesantes, tradicionalistas, comerciantes, miembros del clero, turistas entre otros. Esta movilidad permite el intercambio de experiencias, tradiciones, servicios comerciales, superando los espacios municipales y ampliando la influencia territorial de lo sagrado.

Es pertinente destacar que la imagen del santo y la feligresía no espera en su morada la llegada de los otros santos, sino que sale al encuentro de los "visitantes", estableciéndose lo que popularmente se conoce como "tope de los santos", dirigiéndose luego a la morada del santo anfitrión, fundiéndose en una única 
celebración colectivo. Es en los lugares de "los topes", donde los "anfitriones" y "visitantes" se encuentran y donde se manifiesta la creatividad del fervor religioso popular de los asistentes: estandartes con estandartes, músicos con músicos, promesantes con promesantes y así sucesivamente todas las expresiones colectivas o individuales se expresan.

Con la anterior expresión, se presenta una variante al concepto tradicional de peregrinaciones relacionada a la visita al lugar y la cosa sagrada. En "el tope de los santos", lo sagrado también se mueve, trasgrediendo la división territorial-administrativa de los municipios. Otra particularidad de esta expresión, se da con la participación del municipio de Dolores (un cuarto municipio que se integra), siendo una estancia donde se da "el tope" o encuentro de los santos, pero su santo titular no mueve, sino que ofrece una especie de "refugio" para quienes se mueven en el circuito ritual religioso.

Las peregrinaciones analizadas en este trabajo, siguiendo a Víctor Turner (2005) es la de los feligreses acompañados con sus símbolos, clasificada por este autor como dominantes. Estos símbolos serían los santos e instrumentales que incorpora en su performance: las motivaciones, las formas de pago de promesas, las penitencias, el sentido político, las relaciones familiares, la cosmovisión.

\section{El circuito ritual religioso y la dimensión de la región histórica}

Para iniciar este apartado, es bueno aclara que cuando se habla de región histórica, siguiendo a Ivette García (2004), se hace considerando un espacio geográfico y social, físicomaterial, donde se observan características económicas, sociales, políticas, culturales e ideológicas. A partir de esta aproximación conceptual, es posible aglutinar las nociones de territorio, región, espacio creado, espacio vivido y territorialidad.
Otro aspecto que debe establecerse con claridad, es la concreción de un nuevo tratamiento a la discusión sobre peregrinaciones, procesiones, romerías $y$ recorridos rituales. Todo ello a partir de una realidad concreta verificada en la Meseta de los Pueblos, definida en este estudio como circuito ritual religioso.

Bajo el circuito ritual religioso, el espacio de influencia de lo sagrado se amplía más allá de lo delimitado oficialmente por el estado nacional definido como fronteras municipales. La movilidad de la feligresía en un circuito bajo la tutela de sus santos patronos, hace que las fronteras territoriales administrativas tomen otra dimensión, se redefina, siguiendo patrones culturales creados bajo la convergencia de los rituales particulares.

El circuito ritual religioso hace de la región histórica una porosidad que no es posible encontrar en otras instituciones como las electorales cuya circunscripción es local y responde a la división política administrativa del municipio. De igual manera, los programas gubernamentales, como los de salud tienen la lógica estructural y de funcionamiento local, municipal o regional. Los mataderos locales, llevan la lógica "municipal" o regional.

En la cotidianidad religiosa de la meseta de los pueblos se observa cierta incoherencia entre las expresiones populares de la feligresía católica y la institución expresada en las parroquias y los sacerdotes. Existe una lógica administrativa de las celebraciones religiosas, las cuales son atendidas desde la localidad, de manera que cada parroquia o capilla tiene sus propias celebraciones y no da cabida a una articulación más amplia que incorpore o de cabida a expresiones populares. En las festividades populares que celebran a estos santos, son ellos y la feligresía que lo acompaña los invitados, no los sacerdotes que resguardan su propia "localidad" o parroquia. 
Ante esta realidad, diversas comunidades de los pueblos o ciudades de la Meseta de los Pueblos pertenecientes a la arquidiócesis de Managua se saltan la norma institucional. Pueblos "hermanos" se visitan, aunque esta hermandad responde a realidades históricas, económicas, étnico-culturales, políticas, mítico - mágicas concretas, siendo estos elementos el trasfondo real de las fiestas.

Este trasfondo tiene su anclaje en una cosmovisión dinámica, donde los imaginarios colectivos y la amalgama de sentidos culturales dinamizan y permiten la repetición espacio-temporal anual, así como las separaciones y/o confluencia, en un todo armónico, de lo sagrado y lo profano. De manera que en las estructuras mentales se pueden encontrar mapeos propios que hacen de la realidad una construcción social única, entendida bajo sus propios términos. Al respecto Daniel Sánchez (2010) señala que:

Las sociedades enteras marcan el curso de su dirección de acuerdo con un mapa de la realidad, le llamamos a ésta percepción compartida por el grupo social, una cosmovisión y vemos esa cosmovisión como el corazón de una cultura, funcionando, por un lado, como un marco de referencia que determina como se percibe la realidad, $y$, por otro lado como una fuente de pautas para el comportamiento de las gentes en respuesta a esa percepción. (pág.80)

La cosmovisión efectivamente es el corazón de la cultura. Es el fenómeno invisible que dicta los valores con los que los pueblos se ven, sienten, organizan, estructuran, integran, discriminan o restringen. Es por lo tanto, la concepción de la región histórica un elemento vivo, donde los árboles, piedras, cañadas, ríos, cruces de caminos, el tiempo, las horas y los momentos, adquieren nuevos valores más que el valor aparente, cuantificable y medible.
Los pueblos indígenas ancestrales no se regían por divisiones o límites tal cual se establecieron con la llegada de los europeos a América y luego por la cultura republicana. Eran una especie de "cuerda floja" que permitía el entrecruzamiento de todas ellas, siguiendo criterios variados, de tipo religioso, comercial o lingüístico. Bernardo García Martínez (1987) aclara que esta situación creó gran desconcierto entre los primeros europeos que llegaron a América, de manera que poco a poco, fueron imponiendo sus propias formar de ordenamiento $y$ administración territorial. Pese a ello, las expresiones culturales de organización de los pueblos sometidos, siguieron manifestadas utilizando estrategias diversas para hacerlo.

En la conformación de la región histórica se pueden observar tres momentos: el primero plateado por García Martínez (1987), la presencia de la iglesia y el poder militar, cuya noción centralizadora del orden político territorial europeo se expresa en las cofradías, reducciones de indios, la hacienda, las instituciones estatales y la nobleza indígena. Como bien lo señala Bernardo García Martínez (1987):

Con la desarticulación políticoadministrativa nativa como elemento aglutinador, éste se trasladó al culto de los santos patronos, quienes encontraron en este manejo de bienes y en el desempeño de las funciones rituales correspondientes, la posibilidad de identificación social. En éste contexto la construcción de iglesias jugó un importante papel en el proceso de reordenar el territorio y la creación de nuevos símbolos para la nueva demarcación (pág.76)

El segundo momento, ligado al desarrollo del comercio, trazando nuevas rutas y nuevas demandas comerciales. Esta situación, provoca la creación de rutas comerciales, mercados y consecuentemente actividades productivas y económicas, generando 
desplazamiento de grandes poblaciones. Carlos Bravo Marentes (1989) explica que con ello devino nuevos destinos, alteración de relaciones y manejo de nuevas concepciones de región; uso de moneda, introducción de bestias de cargas que redimensionaron los tiempos, las distancias y los volúmenes de mercancía.

Finalmente, un tercer momento considera la situación de política de los actuales estadosnacionales que separan el territorio por demandas, necesidades reales o creadas por intereses propios o ajenos. En este sentido, las instituciones estatales, los agentes económicos y la estructura productiva, además de los intereses políticos, generan formas organizativas territoriales distintas a las de los grupos sociales minoritarios o subalternos, como la que impera dentro de la lógica festiva de los rituales de santos a que alude este trabajo.

\section{Conclusiones}

Es claro que el tratamiento teórico de las categorías espacio, territorio, región versan más o menos sobre lo mismo, haciendo referencia al elemento físico, en tanto materia donde se reguardan los recursos de los que disponen las sociedades. Pero también es entendido desde una posición humana, dotando al mismo de las características que le imprimen las culturas que definen a los conglomerados sociales. De manera que se transforma en el espacio de la memoria, donde habita la cosmovisión.

La región histórica para los efectos prácticos, teóricos y metodológicos, abarca ambas concepciones. Puede verse su alcance, al referirse a las construcciones históricas surgidas del análisis de los hechos y situaciones culturales que se gestan en el espacio y tiempos precisos.

La meseta de los pueblos, es el escenario preciso donde se entrecruzan elementos contenidos en lo que se llama religiosidad popular, caso concreto de lo que aquí se ha llamado recorrido ritual religioso. La experiencia práctica permite hacer las sugerencias propias en contraste con lo ya referenciado teóricamente como peregrinaciones, romerías, procesiones y traslados rituales. Así, se devela una nueva forma ritual en la que se verifican diferentes expresiones rituales, teóricamente descritos con anterioridad, para dar lugar al entendimiento de uno nuevo de tipo religioso.

Cuando se habla de circuito ritual religioso, se parte de la concepción de región histórica y de las visitas y encuentros de los "santos hermanos" en la Meseta de los Pueblos. A esto se le agrega el tema de la cosmovisión para entender las redimensiones $y$ transformaciones históricas y culturales que intervienen para definir la región histórica.

Finalmente, es posible entender la región histórica desde diferentes ángulos como lo económico, lo medio ambiental, lo político, las redes sociales. Pero también, desde la puesta en escena de los elementos propios de la religiosidad popular expresada con creatividad cada año.

\section{Referencias bibliográficas}

Agís Villaverde, M. (2008) Antropología de la peregrinación, ¿Quiénes son los peregrinos?IX Encuentro de santuarios de España. En: http://www. conferenciaepiscopal.nom.es/pastoral/ turismo/encuentro/xi/marcelinoagis.pdf Consultado el 04 mayo, 2016

Boehm, B. (1997) El enfoque regional y los estudios regionales en México: Geografía, Historia y Antropología. Relaciones año 72 vol XVIII

Bourdieu, Pierre. La identidad y la representación: elementos para una reflexión crítica sobre la idea de región (Análisis). En: Ecuador Debate. Memorias de la izquierda, Quito: 
CAAP, (no. 67, abril 2006): pp. 165-184

Bravo Marentes, C. (1989) Arrieros somos. México: DGCP.

García, I. (2004) Región Histórica - Región deprimida y método retrospectivo. $\mathrm{Su}$ aplicación a un caso. Memoria del Taller de Historia regional y local "Globalización, regiones y naciones. La Habana.

González, J. L. (2000) “Catolicismo popular y tejido cultural”, Estudios, núm. 62-63, ITAM, México, 99 - 119.

Hlúšek, R. (2013). La Peregrinación como demostración de la devoción Guadalupana de los indígenas mexicanos En: Martinez Cárdenes, R. coord. Santuarios, fiestas patronales, peregrinaciones y turismo religioso. Guadalajara: Eumed

Lefebvre, H. (1974) La producción del espacio. Revista de sociología, Núm.: 3, 219-229

Lindón, A. y Hiernaux, D. (2006) Tratado de geografía humana, México: Anthropos Ed. Montañez, Gustavo; et al. (1997). Geografía y Ambiente: Enfoques y Perspectivas. Santafé de Bogotá: Ediciones Universidad de la Sabana.

Montañez G y Delgado O. (1998) Espacio, territorio y región. Conceptos básicos para un proyecto Nacional. Cuadernos de Geografía. Vol III No 1-2, $120-134$

Mudarra Vidal, T. (2015) Las romerías como hechos sociales. Castellón - España: UNED

Sánchez, D. (2010) El concepto de cosmovisión. Kiaros $N^{\circ} 47,79-93$

Turner, V. (2005) La selva de los Símbolos: aspectos del ritual Ndembu. Madrid: Siglo XXI.

Turner, V \& Turner, E. (1978). Imagen y peregrinos en la cultura cristiana. Perspectivas antropológicas. Nueva York: Columbia University Press 